Polymer Journal, Vol: 5, No. 1, pp 1-10 (1973)

\title{
Electronic Structure and Energy of the Complexes: Methyllithium-Unsaturated Polar Monomer
}

\author{
Yu. Ye. Eizner, B. L. Erussalimsky, and E. B. Milovskaya \\ Institute of High Molecular Weight Compounds of the \\ Academy of Sciences of the USSR, Leningrad
}

(Received May 19, 1972)

\begin{abstract}
The electronic structure and the energy of $\mathrm{CH}_{3} \mathrm{Li}$ and its dimer have been calculated using a CNDO/2-method. The geometry of a planar rhombus was adopted for $\left(\mathrm{LiCH}_{3}\right)_{2}$. Variation of the rhombus dimensions led to equilibrium distances of $\mathrm{Li}-\mathrm{Li}=1.65 \AA$ and $\mathrm{C}-\mathrm{C}=3.85 \AA$. The dimerization energy was equal to $430 \mathrm{kcal} /$ mol. Dimerization decreased the energy of all molecular orbitals including the frontier ones, i.e., it increased the acidity. The calculations for the complexes of $\mathrm{LiCH}_{3}$ with formaldehyde and acrylonitrile were carried out for various relative positions of the components. Sometimes the energy minimum was found when $\mathrm{LiCH}_{3}$ was located out of the plane of the Lewis base near to $\mathrm{C}$ atom which is adjacent to the heteroatom. The complexation energies of $\mathrm{LiCH}_{3}$ with acrolein, vinyl formate and methyl acrylate were also calculated and found to be 120,80 and $140 \mathrm{kcal} / \mathrm{mol}$ respectively. It corroborates the assumption that conjugated bases should form with organometallics complexes of higher stability than the unconjugated ones (the complexation energy with formaldehyde was equal to $100 \mathrm{kcal} / \mathrm{mol}$ ). The complexation energy with acrylonitrile was found to be $180 \mathrm{kcal} / \mathrm{mol}$. This correlates with the higher activity of this monomer when compared to methyl acrylate in anionic systems and correlates with the lower activity of acrylonitrile compared to methyl acrylate if they are in the same system but in the presence of a small amount of strong Lewis base competing for the complexing conter.

KEY WORDS Methyllithium / Carbonyl Bases / Acrylonitrile / Ionic Polymerization / Complex Geometry / Complexation Energy / MO LCAO SCF Calculations / Reactivity Indices /
\end{abstract}

As shown recently, the following calculated values correlate with the activity of vinyl monomers in the cationic propagation reaction: the total negative charge of the $\beta$-C atom, the $\pi$ component of this charge, and the sum (also negative) of the total charges of all atoms of the $\mathrm{CH}_{2}$ group. ${ }^{1}$ We failed to find a similar correlation for the vinyl anionic polymerization, i.e., the correlation of the positive charge characteristics of the $\beta$-C atoms in the monomers with the activity of the latter. We suggested that the supposed correlation was perturbed by the complexation of the monomer with the positive counter ion of the growing chain, this complexation preceding the inclusion of the monomer in the $\mathrm{C}$-metal bond. ${ }^{2}$ This suggestion was confirmed experimentally. The copolymerization of acrylonitrile (AN) with methyl acrylate (MA), initiated by an organolithium compound with a coordinatively saturated counter ion, led to results which agree with the quantumchemical data for isolated monomers. ${ }^{3,4}$

One of the purposes of the present work was to attempt to use the quantum-chemical data relating to the complexes of AN and MA with the simplest alkyl lithium $\mathrm{CH}_{3} \mathrm{Li}$ for evaluating (a) changes in the monomer's electronic structure induced by complexation; (b) the possibility of selective complexing of one of the monomers in the system RLi-AN-MA; (c) the influence of complexing on the activity of the $\mathrm{R}-\mathrm{Li}$ bond.

The second task is connected with radical polymerization of vinyl monomers initiated by $\mathrm{R}_{3} \mathrm{Al}$-acyl peroxide systems. As shown by a detailed kinetic investigation of these systems carried out with methyl methacrylate (MMA), 
vinyl acetate (VA) and AN, the monomer takes part in the formation of the initial free radicals. ${ }^{5}$ This stage includes a transition state in which peroxide acts as a bidentate electron donor and reacts with the complex $\mathrm{R}_{3} \mathrm{Al} \cdot \mathrm{M}$, which acts as a bidentate electron acceptor. The acceptor positions are $\mathrm{Al}$ and the vinyl group of the monomer in the complex. Hence, it seemed again to be interesting to investigate the change in electronic structure of the monomer induced by its complexation with metal alkyl. Assuming that the esters which were studied experimental$1 y^{5}$ complex with the metal alkyls through the ester carbonyl group, ${ }^{6}$ we attempted to investigate the dependence of the stability of these complexes on the conjugation effects in the monomer molecules. For this purpose the following complexes were calculated: the complexes of $\mathrm{CH}_{3} \mathrm{Li}$ with (1) formaldehyde (FA) as the simplest carbonyl-containing molecule; (2) acrolein (A) as the simplest conjugated carbonyl compound; (3) vinyl formate (VF) as the simplest unsaturated unconjugated carbonyl compound; and 4) MA (see above). Of course, the use of $\mathrm{CH}_{3} \mathrm{Li}$ instead of $\mathrm{R}_{3} \mathrm{Al}$ hampers a comparison of the calculated values with the experimental data because $d$ orbitals are absent in $\mathrm{Li}$ and the steric structures of Li- and Al-alkyls are different. However, this replacement facilitates the calculation for the complexes containing relatively large electrondonor molecules, such as VF and MA.

Confining ourselves to the simplest metal alkyl, $\mathrm{LiCH}_{3}$, we used it in the monomeric form although in reality its molecules are associated. We have done this because we are not interested in the $\mathrm{LiCH}_{3}$ itself but primarily because it is the simplest model of the active center for anionic polymerization. The structure of the active centers is not sufficiently well known to model it with certainty. One cannot be sure that this structure coincides in all details with the structure of the corresponding free metal alkyl. In particular there is a difference in the degree of association: $\mathrm{LiCH}_{3}$ exists as a rule in a tetrameric or hexameric form, ${ }^{7} \mathrm{M}_{n} \mathrm{Li}$ exists as active dimeric macromolecules (where $\mathbf{M}_{n}$ is a hydrocarbon macromolecular chain), ${ }^{8}$ and as has been shown recently $\mathrm{M}_{n}(\mathrm{AN})_{m} \mathrm{Li}$ where $m=1,2$ exists as chains which are not associated at all (in nonpolar media). ${ }^{9}$ Hence, we preferred to use our computational possibilities for considering monomers of various types and for varying the geometry of the compounds used.

For such large systems as $\mathrm{CH}_{3} \mathrm{Li} \cdot \mathrm{MA}$ (which includes 41 atomic orbitals (AO) in the valence shells) quantum-chemical calculations using middle-size computers can only be carried out by semiempirical methods. We have used the CNDO/2 method. ${ }^{10-13}$ As shown recently, this relatively simple method describes the geometry as well as more detailed semiempirical and nonempirical methods. ${ }^{14-16}$ On the other hand, this method seems to underestimate electronic repulsions and, hence, to overestimate the advantages of the multibonded conformations. ${ }^{17}$

\section{SOME FEATURES OF METHYLLITHIUM AGGREGATES}

We began with $\mathrm{CH}_{3} \mathrm{Li}$. According to Sutton we assumed all angles in $\mathrm{CH}_{3}$ to be tetrahedral and the $r(\mathrm{C}-\mathrm{H})$ distances to be equal to $1.09 \AA .^{18}$ Varying only the $r(\mathrm{C}-\mathrm{Li})$ distance we obtained the equilibrium value $r_{0}(\mathrm{C}-\mathrm{Li})=1.89 \AA$ (the experimental value is equal to $2.10 \AA^{19}$ ) and the charge distribution shown in Figure 1. ${ }^{*}$ The
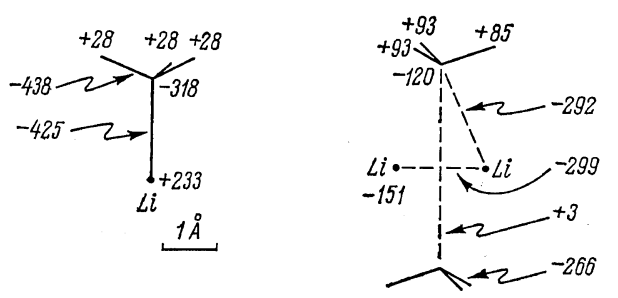

Figure 1. Charge distribution $\left(\times 10^{3}\right)$ in $\mathrm{CH}_{3} \mathrm{Li}$ and in $\left(\mathrm{CH}_{3} \mathrm{Li}\right)_{2}$ in configurations corresponding to the total energy minimum. Arrows indicate the values (in $\mathrm{kcal} / \mathrm{mol}$ ) of contributions $E_{i k}$ from the atom pairs to the $E_{\text {tot }}$.

great number of vacant AO's on the $\mathrm{Li}$ atom near the alkyl group (a potential electron donor) causes the well-known phenomenon of strong aggregation of the RLi molecules (see, e.g., ref 7). Proceeding from the geometry of the dimer

* The symbols $\mathrm{C}$ and $\mathrm{H}$ are omitted in all figures. 
$\left(\mathrm{CH}_{3} \mathrm{Li}\right)_{2}$ shown in Figure 1 and varying only the distances $r(\mathrm{Li}-\mathrm{Li})$ and $r(\mathrm{C}-\mathrm{C})$, the minimum of $\Delta E=E_{\mathrm{tot}}\left[\left(\mathrm{CH}_{3} \mathrm{Li}_{2}\right)\right]-2 E_{\mathrm{tot}}\left[\mathrm{CH}_{3} \mathrm{Li}\right]$ was found ( $E_{\text {tot }}$ is the total energy of the system). This minimum, corresponding to the distances $r_{0}(\mathrm{Li}-\mathrm{Li})=1.65 \AA$ and $r_{0}(\mathrm{C}-\mathrm{C})=3.85 \AA$, was found to be equal to $-431 \mathrm{kcal} / \mathrm{mol}$. The path of this search (shown partially in Figure 2) gives

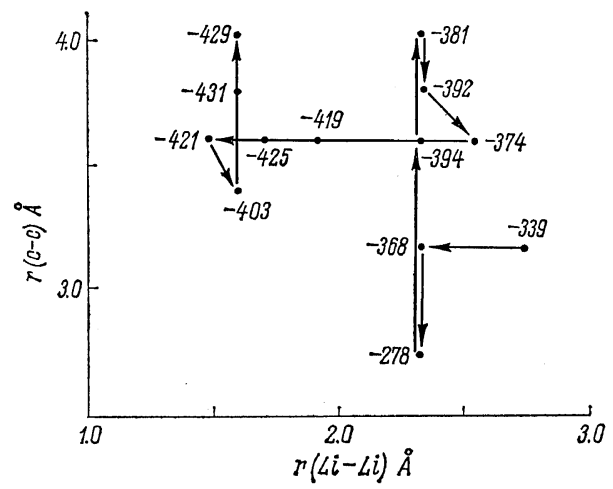

Figure 2. The path of the search for the stable configuration of the dimer $\left(\mathrm{CH}_{3} \mathrm{Li}\right)_{2}$. The values of $\Delta E$ (see the text) are shown at the points in $\mathrm{kcal} / \mathrm{mol}$.

an idea of the potential surface of the aggregation process. It is interesting to note the low value of $r_{0}(\mathrm{Li}-\mathrm{Li}),{ }^{*}$ the high value of $|\Delta E|$ and the remarkable electron density on the $\mathrm{Li}$ atom. We shall compare the electron characteristics of $\mathrm{Li}$ in $\mathrm{CH}_{3} \mathrm{Li}$ and in its dimer. In the first case 0.555 of the electron is concentrated in the $\sigma$ orbitals (with respect to the $\mathrm{Li}-\mathrm{C}$ bond) of the $\mathrm{Li}$ atom and 0.106 of the electron is placed in each of the $2 p$-orbitals perpendicular to the $\mathrm{Li}-$ $\mathrm{C}$ bond. In the dimer 0.575 of the electron is placed in the $\sigma$-orbitals (here with respect to the $\mathrm{Li}-\mathrm{Li}$ bond), 0.184 is placed in the AO perpendicular to this $\sigma$ bond and to the dimer's plane and 0.392 is placed in the AO perpendicular to the $\mathrm{Li}-\mathrm{Li}$ bond but lying in the dimer's plane. This suggests that the energy consumption for the promotion of the electrons from the $\mathrm{C}$ atoms and from the $\mathrm{C}-\mathrm{Li}$ and $\mathrm{C}-\mathrm{H}$ bonds to the

* The distance $r_{0}$ in $\mathrm{Li}_{2}$ is equal to $2.672 \AA^{20,21}$; twice the $\mathrm{Li}^{+}$radius in the $\mathrm{LiF}$ crystal is equal to $1.82 \AA^{22}$; according to Pauling, twice the $\mathrm{Li}^{+}$-ionic radius is equal to $1.20 \AA^{23}$. highly energetic $\mathrm{Li} \mathrm{AO}$ is more than compensated for by the decrease in energy caused by the formation of the $\mathrm{Li}-\mathrm{Li}$ bond. Apart from the $\sigma$-component the latter contains two $\pi$-components: one of them is perpendicular to the dimer's plane (its bond order $P$ is equal to 0.184 ) and the other one is in this plane $(\mathrm{P}=0.300)$. The "triple" character of the $\mathrm{Li}-\mathrm{Li}$ bond may explain its contraction and high complexing energy.**

We have no information about the experimental dimensions of $\mathrm{CH}_{3} \mathrm{Li}$ aggregates in the gas phase. As the CNDO/2-method usually leads to $r_{0}$-values differing from the experimental ones only by a few percent, ${ }^{26}$ we suggest that our value $1.65 \AA$ is close to reality. The value for $r_{0}(\mathrm{Li}-\mathrm{Li})$ found in crystaline $\mathrm{C}_{2} \mathrm{H}_{5} \mathrm{Li}(2.32-$ $2.63 \AA)^{27}$. may be ascribed to packing peculiarities. Recently the analogy between alkaly metals and hydrogen was mentioned and the existence of lithium bonds linking two strong electron donors was predicted. ${ }^{28}$ As follows from the data in Figure 1, a large number of extensive vacant AO's (although of a higher energy than the single valence $\mathrm{AO}$ of the $\mathrm{H}$ atom) permits lithium also to form bridge bonds between atoms of lower negativity than $\mathrm{N}, \mathrm{O}$ and halogens, i.e., bonds similar to the multicentered ones in boranes. ${ }^{29}$ Indeed, the value of $r_{0}(\mathrm{C}-\mathrm{C})=3.85$ $\AA$ excludes the overlapping of the AO's of the two $\mathrm{C}$ atoms; the latter are bound only through the $\mathrm{Li}$ atoms.

It is necessary to emphasize that our results agree with the assumption formulated by Seitz and Brown with regard to the conformation of $(\mathrm{RLi})_{4}$ with alkyl groups outside the aggregate ${ }^{30}$ and confirmed by McKeever, et al., ${ }^{31}$ and disagree with the opposite conclusion made by Brown, et al. ${ }^{32}$ Finally, a relatively small elongation of $r_{0}(\mathrm{C}-\mathrm{Li})$ up to $2.10 \AA$ and a decrease in the energy of the molecular orbitals (MO) owing to aggregation must be noted. In particular, the energy of the highest occupied MO (HOMO) decreases from -288 to $-319 \mathrm{kcal} / \mathrm{mol}$

** Peyton and Glaze obtained a similar value of $\Delta E=-398 \mathrm{kcal} / \mathrm{mol}$ using also the CNDO/2-method. ${ }^{24}$ These authors have not mentioned whether the dimer's geometry was varied. The CNDO/1-method was used by Cowley and White for $\left(\mathrm{CH}_{3} \mathrm{Li}\right)_{4}{ }^{25}$. 
and that of the lowest vacant one (LVMO) decreases from +19.5 to $-36.5 \mathrm{kcal} / \mathrm{mol}$. The "rigidity" of the $\mathrm{Li}-\mathrm{C}$ bond in $\mathrm{LiCH}_{3}$ may be explained qualitatively by the shape of its frontier MO's both of which are of the $\sigma$-type:

$$
\begin{aligned}
\mathrm{HOMO}= & {\left[0.312(2 s)-0.226\left(2 p_{z}\right)\right]_{\mathrm{Li}} } \\
& +\left[0.176(2 s)+0.852\left(2 p_{z}\right)\right]_{\mathrm{C}} \\
& -3[0.178(1 s)]_{\mathrm{H}} \\
\mathrm{LVMO}= & {\left[0.813(2 s)+0.564\left(2 p_{z}\right)\right]_{\mathrm{Li}} } \\
& +\left[-0.075(2 s)+0.118\left(2 p_{z}\right)\right]_{\mathrm{C}} \\
& -3[0.022(1 s)]_{\mathrm{H}}
\end{aligned}
$$

(the axis $z$ is directed from $\mathrm{C}$ to $\mathrm{Li}$ ). This structure of the frontier MO's means that $98 \%$ of the electron accepted by the $\mathrm{LiCH}_{3}$ molecule is placed in the nonbonding Li orbital and $86 \%$ of the electron donated by this molecule is placed on the $\mathrm{C}-\mathrm{H}$ bonds. Hence, none of the charge displacements in $\mathrm{LiCH}_{3}$ which assompany its complexation should strongly affect the $\mathrm{Li}-\mathrm{C}$ bond. Since the energy of the HOMO is approximately equal to $-I$, where $I$ is the ionization potential of the molecule (see ref 33), and the energy of the LVMO is a qualitative characteristic of the electron affinity, ${ }^{34}$ the decrease in both of these MO energies means that the dimerization does not decrease the acidic properties of the lithium alkyls. In contrast to this, on dimerization the changes in electronic structure increase the acidic properties, and one may suppose that this surprising phenomenon might be expected in other cases of aggregation of metal alkyls. This effect is caused by the appearance of many new bonds in the aggregate; for example in $\left(\mathrm{LiCH}_{3}\right)_{2}$ there are five bonds between heavy atoms compared with two such bonds in $2 \mathrm{LiCH}_{3}$. These appearance of bonds leads to the stabilization of both occupied and vacant MO's and consequently to an increase in electron deficiency. However, the real acidity of a molecule is determined not only by its electronic structure but also by the steric accessibility of the acidic sites in it. The true aggregated form of $\mathrm{CH}_{3} \mathrm{Li}$ is known to be a tetramer and not a dimer. ${ }^{7}$ According to Seitz and Brown ${ }^{30}$ and to McKeever, et al., ${ }^{31}$ the acidic

* As the LVMO in the dimer is localized on the $\mathrm{Li}$ atoms (just as in $\mathrm{CH}_{3} \mathrm{Li}$, although to a lesser extent) one can suggest the same phenomenon occurs. in the case of the tetramer.
$\mathrm{Li}$ atoms* in the tetramer are screened by alkyl groups; hence, the "real acidity" of $\left(\mathrm{CH}_{3} \mathrm{Li}\right)_{4}$ is much lower than the theoretical one.

\section{THE GEOMETRY OF FORMALDEHYDE- METHYLLITHIUM COMPLEX}

The smallest of the complexing molecules we have considered, formaldehyde (FA), was used in searching for the mutual orientation of $\mathrm{CH}_{3} \mathrm{Li}$ and the carbonyl base (CB) which would correspond to the maximum absolute value of the complexation energy $\Delta E=E_{\text {to }}\left[\mathrm{CB}+\mathrm{CH}_{3} \mathrm{Li}\right]-$ $E_{\text {tot }}[\mathrm{CB}]-E_{\text {tot }}\left[\mathrm{CH}_{3} \mathrm{Li}\right]$. The geometry of both complex components was assumed to be invariable; only their mutual disposition was varied. According to our results we assumed that $r_{0}(\mathrm{Li}-\mathrm{C})$ was $1.9 \AA$ for $\mathrm{LiCH}_{3}$; for FA we used the results obtained from microwave spectroscopy: ${ }^{35}$ $r_{0}(\mathrm{C}=\mathrm{O})=1.208 \AA, r_{0}(\mathrm{C}-\mathrm{H})=1.116 \AA, \angle \mathrm{HCH}=$ $116^{\circ} 30^{\prime}$. The path of this search and its results are shown in Figure 3. The charge distributions for different steps of this investigation are given in Table I. It follows from Figure 3 that the

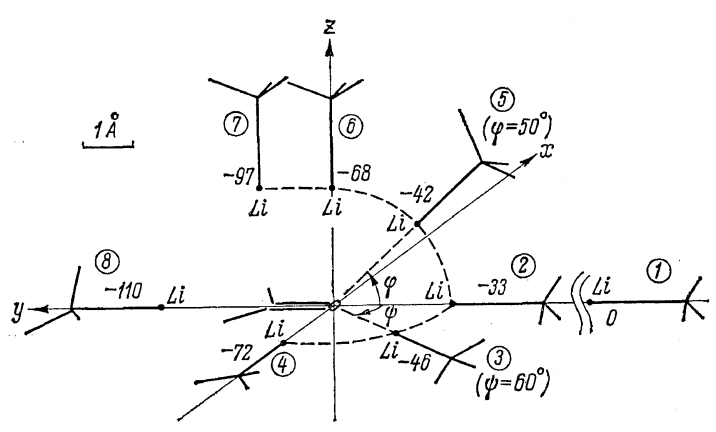

Figure 3. The dependence of the complexation energy on the $\mathrm{CH}_{3} \mathrm{Li}$ and $\mathrm{HCHO}$ mutual orientation. The values of $\Delta E$ are shown in $\mathrm{kcal} / \mathrm{mol}$ at the $\mathrm{Li}$ atom. Position numbers are shown in circles. The equilibrium distances were found: $r_{0}(\mathrm{Li}-\mathrm{C})=2.4 \AA$ in position 2 and $r_{0}(\mathrm{Li}-\mathrm{C})=2.3 \AA$ in position 8 .

results obtained are in contradiction with the usual ideas which are illustrated by positions $1-2$. The most advantageous approach is that of the $\mathrm{Li}$ atom to the $\mathrm{CH}_{2}$ group rather than to the $\mathrm{O}$ atom. As this result is unexpected and the argumentation based on the semiem- 
Table I. Charges on the atoms of the components of the complex $\mathrm{CH}_{3} \mathrm{Li} \cdot \mathrm{HCHO}$

\begin{tabular}{|c|c|c|c|c|c|c|}
\hline \multirow{2}{*}{ 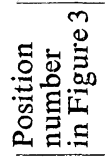 } & \multicolumn{3}{|c|}{$\mathrm{CH}_{3} \mathrm{Li}$} & \multicolumn{3}{|c|}{$\mathrm{HCHO}$} \\
\hline & $\mathrm{Li}$ & $\mathrm{C}$ & $\mathrm{H}$ & $\mathrm{O}$ & $\mathrm{C}$ & $\mathrm{H}$ \\
\hline 1 & +0.233 & -0.318 & +0.028 & -0.183 & +0.222 & -0.019 \\
\hline 2 & +0.101 & -0.305 & +0.023 & -0.132 & +0.258 & +0.006 \\
\hline 3 & +0.080 & -0.301 & +0.021 & -0.122 & +0.255 & $\begin{array}{l}+0.008 \\
+0.016\end{array}$ \\
\hline 4 & +0.011 & -0.295 & +0.021 & -0.106 & +0.263 & $\begin{array}{r}+0.015 \\
+0.049\end{array}$ \\
\hline 5 & +0.083 & -0.303 & +0.023 & -0.125 & +0.258 & +0.010 \\
\hline 6 & +0.021 & -0.297 & +0.023 & -0.104 & +0.258 & +0.025 \\
\hline 7 & -0.037 & -0.290 & +0.023 & -0.090 & +0.248 & +0.049 \\
\hline 8 & -0.104 & -0.285 & +0.025 & -0.114 & +0.266 & +0.080 \\
\hline
\end{tabular}

pirical methods of the type suggested by Pople, et al., ${ }^{10-13}$ is not sufficient, we shall attempt to explain it qualitatively. First of all it should be noted that the usual idea is based on the idea that the main role is that of Coulomb interaction of the polar complexing agents. According to the valence-bond theory (see, e.g., ref 23) this idea also takes into account the fact that the unshaired electron pairs of the $\mathrm{O}$ atom are placed on the hybrid orbitals directed from the $\mathrm{CH}_{2}$ group. Hence, one can assume that just these electrons are transferred to the vacant AO's of the $\mathrm{Li}$ atom in the course of complex formation. However, the Coulomb energy is low: Figure 3 and Table I show that its value is equal to several $\mathrm{kcal} / \mathrm{mol}$ (this is a typical value, see, e.g., ref 36). Usually Coulomb energy never exceeds $10-20 \%$ of $\triangle E$. The assumption that the electron transfer proceeds to lithium just from oxygen is not completely confirmed either. While the LVMO in $\mathrm{CH}_{3} \mathrm{Li}$ is actually almost entirely localized on the $\mathrm{Li}$ atom (see above), only $58 \%$ of the electron donated by FA is transferred from the $O$ atom and the rest is transferred from the $\mathrm{CH}_{2}$ group:

$$
\begin{aligned}
\mathrm{HOMO}= & 0.761\left(2 p_{x}\right)_{\mathrm{o}}-0.302\left(2 p_{x}\right)_{\mathrm{C}} \\
& +0.406(1 s)_{\mathrm{H}_{1}}-0.406(1 s)_{\mathrm{H}_{2}}
\end{aligned}
$$

(the axis $x$ connects the $\mathrm{H}$ atoms). Consequently, one may assume that when the complexing agents approach each other and their electron shells overlap, i.e., when a possibility exists for: (a) electrons transferring from one molecule to the other and (b) electrons concentrating in the intermolecular space then, the stability of the complex is determined just by the intensity of this overlapping. On the other hand, the overlapping of the electron shells of any pair of atoms is greater the smaller the difference in the size of these shells. Since the inverse Slater exponents for the $\mathrm{Li}, \mathrm{C}$ and $\mathrm{O}$ atoms are equal to 0.82 , 0.32 and $0.23 \AA$, respectively (see, e.g., ref 37 ), it follows that at equal distances between the atoms the overlapping integrals for AO's of the $\mathrm{C}$ and $\mathrm{Li}$ atoms are $1.2-1.6$ times greater than the integrals for AO's of the $\mathrm{O}$ and $\mathrm{Li}$ atoms. However, intensive repulsion between any two atoms begins at the distance at which the core of one of them penetrates the electron shell of the other and the repulsion of the cores is no longer compensated for by the attraction of the cores to the electron shells. Hence, these distances must be determined first of all by the size of the larger reacting atom and must be similar to each other in both these cases.

We should emphasize that all these explanations are qualitative. We must also remember that our calculations were based on the CNDO/ 2-approach in which the advantage of compact conformations is sometimes overestimated. Nevertheless our results cast doubt on the traditional ideas about the geometry of the donor-acceptor complexes. At any rate this conclusion concerns the cases characterized by comparatively high energy for the complexes which greatly exceeds the van der Waals interaction energy.

\section{THE COMPLEXATION OF METHYLLITHIUM WITH SOME MONOMERS}

The position of $\mathrm{CH}_{3} \mathrm{Li}$ in relation to the other CB's was not varied. Taking into account the results for FA we placed $\mathrm{CH}_{3} \mathrm{Li}$ on the normal to the $\mathrm{CB}$ plane passing through the $\mathrm{C}$ atom of the $\mathrm{C}=\mathrm{O}$ group at a distance of $2.3 \AA$ between the $\mathrm{Li}$ atom and the $\mathrm{CB}$ plane. The geometry of A and MA was taken from the experimental work of Wagner, et al. ${ }^{38}$ and Ukaji ${ }^{39}$ respectively, but both molecules were assumed to be planar. For VF the "standard geometry" of PopleGordon $^{40}$ was used. 


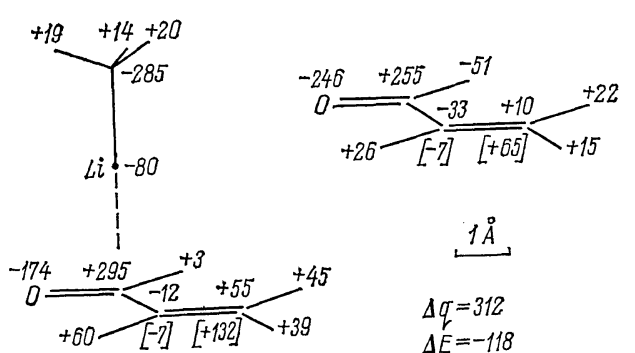

(I)

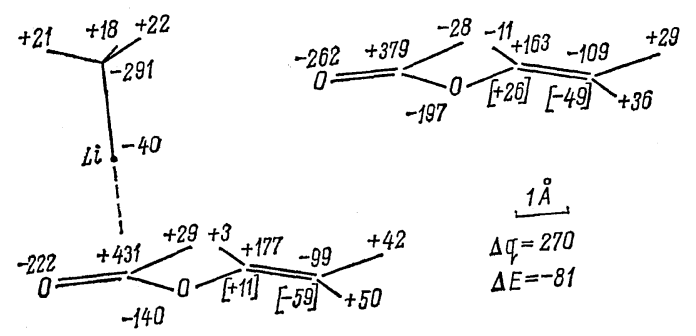

(II)

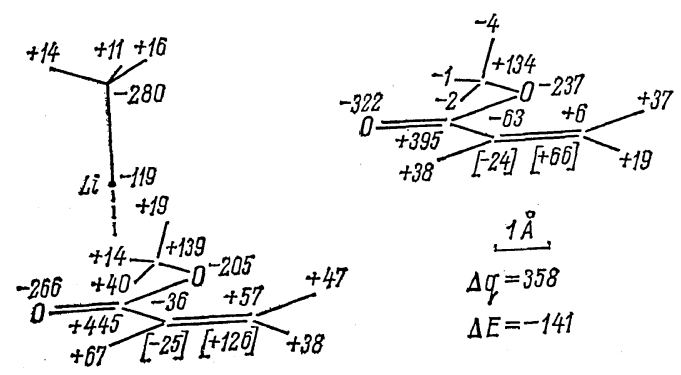

(III)

Figure 4. Results of calculation of $\mathrm{A}(\mathrm{I}), \mathrm{VF}(\mathrm{I})$, $\mathrm{MA}(\mathrm{III})$ and their complexes with $\mathrm{CH}_{3} \mathrm{Li}$. Atom charges $\left(\times 10^{3}\right)$ are shown near the atoms and in the square brackets are shown their $\pi$-components. $\Delta E$ is the complexation energy (in $\mathrm{kcal} / \mathrm{mol}$ ), $\Delta q$ is the value of the charge $\left(\times 10^{3}\right)$ displaced to the methyl lithium.

The results are given in Figure 4. The difference between the charge distribution in the isolated MA molecule obtained by us and by Geller, et al., ${ }^{41}$ (see also ref 42) is caused by different conformations. Considering the system $\mathrm{CH}_{3} \mathrm{Li}-\mathrm{AN}$, ${ }^{*}$ we have again moved the first

* The geometry of AN was taken from ${ }^{43}$, all angles at the $\beta-C$ atom were assumed equal to $120^{\circ}$ and all $\mathbf{C}-\mathrm{H}$ distances equal to $1.086 \AA$.

component with respect to the second one. The sequence of the search of the $E_{\text {tot }}$ minimum

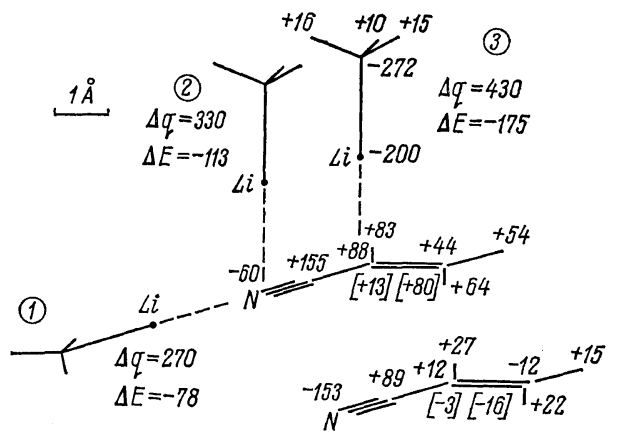

Figure 5. Results of calculation of $\mathrm{AN}$ (in the lower right corner) and its complex with $\mathrm{CH}_{3} \mathrm{Li}$. Designations coincide with those in Figure 4. Charge distribution in complex corresponds to the position 3 .

(similar to that given in Figure 3 ) is shown in Figure 5. In all cases the equilibrium distance between $\mathrm{Li}$ and $\mathrm{N}$ in position 1 and between $\mathrm{Li}$ and the AN plane during the displacement from 2 to 3 were found equal to $2.1 \AA$. A comparison of Figure 4 and 5 shows that the "anionic character" of MA and AN as polymerizable subztances (as estimated by the charge on the $\beta$-C atom of the vinyl group ${ }^{1}$ ) increases almost to the same extent as a result of complexation with Lewis acids. Complexation enhances other monomer characteristics (see Table II) which may be associated with the ability of the monomer to take part in the anionic propagation reaction. ${ }^{* *}$

The figures reported enable us to conclude with certainty that complexation with a strong Lewis

Table II. Some characteristics of MA and AN and their complexes with $\mathrm{CH}_{3} \mathrm{Li}$

\begin{tabular}{|c|c|c|c|c|}
\hline $\begin{array}{l}\text { Characte- } \\
\text { ristic }\end{array}$ & $\begin{array}{c}E_{\mathrm{LVMO}} \\
\mathrm{kcal} / \\
\mathrm{mol}\end{array}$ & $\begin{array}{c}\pi \text {-Order } \\
\text { of the } \\
\text { vinyl } \\
\text { bond }\end{array}$ & $\begin{array}{l}\text { Vinyl bond } \\
\text { contribu- } \\
\text { tion } E_{i k} \\
\text { to the } \\
E_{\text {tot, kcal/ }} \text { mol } \\
\text { mol }\end{array}$ & $\begin{array}{l}\text { Vinyl } \\
\text { bond } \\
\text { elonga- } \\
\text { tion in } \\
\text { com- } \\
\text { plex, }{ }^{44} \AA\end{array}$ \\
\hline MA & 58 & 0.950 & -1020 & \\
\hline $\mathrm{CH}_{3} \mathrm{Li} \cdot \mathrm{MA}$ & 23 & 0.918 & -990 & 0.01 \\
\hline $\mathrm{AN}$ & 78 & 0.960 & -1030 & \\
\hline $\mathrm{CH}_{3} \mathrm{Li} \cdot \mathrm{AN}$ & 23 & 0.917 & -975 & 0.02 \\
\hline
\end{tabular}

** A detailed comparison with the experiment was not carried out. 
acid sharply enhances the "anionic character" of MA and AN as polymerizable compounds. However, according to all parameters the uncomplexed MA exhibits a higher anionic activity than the uncomplexed AN; complexation does not change the order of the relative activity of these monomers. On the other hand, the data in Figures 4 and 5 show that $\mathrm{AN}$ forms a more stable complex with $\mathrm{CH}_{3} \mathrm{Li}$ than $\mathrm{MA}$ as the $\Delta E$-values are approximately equal to -180 and $-140 \mathrm{kcal} / \mathrm{mol}$ respectively. Hence, one may suggest that the higher relative activity of AN in the copolymerization of the system AN-MAcoordinatively unsuturated anionic initiator (see ref 3,4 ) is caused by the selection of a monomer of higher basicity. The higher calculated complexing strength of AN with organometallics correlates with the greater complexing abtlity of AN as compared to MMA with respect to $i$ $\mathrm{Bu}_{3} \mathrm{Al}^{45}$ Althoung $i$ - $\mathrm{Bu}_{3} \mathrm{Al}$ and $\mathrm{CH}_{3} \mathrm{Li}$ are very different Lewis acids, one may suppose that the order of activities of two bases (in our case-of AN and of MA) is retained for a rather large group of acids. The basic properties of MA and MMA are probably also similar. The higher basicity of AN agrees also with the interpretation of the kinetic results concerning the initiation system $\mathrm{R}_{3} \mathrm{Al}$ - peroxide. ${ }^{5 *}$

We shall compare the data on various CB's. The greatest complex stability was observed if $\mathrm{CH}_{3} \mathrm{Li}$ was placed in the direction of the maximum $\pi$-electron density (see Figure 3 ). This means that the $\pi$-conjugation in the $C B$ may influence the ability of the $\mathrm{CB}$ to form a complex with metal alkyls. Data in Figures 3 and 4 confirm this suggestion. Compound $\mathrm{A}$, which in contrast to FA contains a conjugation chain, forms a more stable complex than the latter. The conjugation chain in VF is interrupted by the ether oxygen and the complex is actually weaker than that formed by A. The ether oxygen in MA does not interrupt the conjugation chain. On the contrary, in MA the $O$ atom enriches the conjugation by complementary electrons and the MA-complex is found to be the most stable of all the above-mentioned CB-complexes. Con-

* The ideas formulated in ref 46 were revised in ref 5 on the basis of the NMR-data obtained for the complexes of $i$ - $\mathrm{Bu}_{3} \mathrm{Al}$ with monomeres ${ }^{45}$. sidering the complexation induced changes in the reactivities of these monomeric CB's, one must bear in mind that in a sense the CB's under consideration belong to different types. According to their electronic structure, the substances $A$ and MA are typical monomers for anionic polymerization. They are distinguished by $\mathrm{CH}_{2}$-groups positive charges which are enhanced by complexation. The LVMO's of both CB's have a $\pi$-symmetry and loose their vinyl bonds as it could be expected for anionic monomers. These orbitals remain over $90 \%$ localized on the monomer when a complex is formed with $\mathrm{CH}_{3} \mathrm{Li}$ and their energy decreases (for $\mathrm{A}$ from 48 to $9 \mathrm{kcal} / \mathrm{mol}$, for MA-see Table II). In the course of complexation the vinyl group becomes weaker. In A its order decreases from 0.926 to 0.893 and $E_{i k}$ increases from -1010 to $-980 \mathrm{kcal} / \mathrm{mol}$ : the data for MA were reported above. The LVMO in VF, as well as MA, A and $\mathrm{AN}$, has a $\pi$-symmetry and looses the vinyl bond. However, the charge characteristics of the $\mathrm{CH}_{2}$ group in this monomer are negative and remain negative in its complex. In the vinyl bond of VF the weakening induced by complexation with $\mathrm{CH}_{3} \mathrm{Li}$ is small. The bond order changes from 0.966 to 0.962 and $E_{i k}$ changes from -1045 to $-1040 \mathrm{kcal} / \mathrm{mol}$. This corresponds to a bond elongation of only $0.001 \AA$. It is noteworthy that cationic characteristics of VF were found to be as indistinct as anionic ones. ${ }^{1}$

Comparing these results with the experimental data we can note that complexation increases the positive charge of the vinyl bond in all cases considered. These charges for the compounds under consideration are as follows:

\section{A VF MA AN}

Monomer

$\begin{array}{lllll}0.040 & 0.108 & 0.037 & 0.064\end{array}$

Its complex with $\mathrm{CH}_{3} \mathrm{Li} \quad \begin{array}{llll}0.187 & 0.173 & 0.173 & 0.333\end{array}$

This means that the ability of the vinyl group to coordinate with an electron-donor center increases when a complex is formed with a Lewis acid. This conclusion agrees with the ideas formulated in ref 5, 47. In contrast to propagation reaction which occurs only if the ultimate link of the growing chain approaches the $\beta-\mathrm{C}$ atom of the monomer vinyl group, the total charge 
of the vinyl group is of importance in the case considered in the ref 5,47 where the reaction of complexation of CB's with the metal alkyls was studied. The calculated weakening of the vinyl bond in MA and the absence of this calculated weakening in VF also agree with the experimental data since the effect of the vinyl bond elongation in MMA and its absence in VA were observed spectroscopically. ${ }^{47}$ As regards the monomer calculations, these differences can be explained by the different symmetries of the HOMO's. This orbital has a $\pi$-symmetry in MA and a $\sigma$-symmetry in VF with the HOMO in VF localized on the $\mathrm{O}$ atom of the $\mathrm{C}=\mathrm{O}$ group. One may suggest that the electronic structure of the monomers studied spectroscopically is similar to the calculated structures because of the similarity of the conjugation types. The calculated sequence of stabilities for the complexes is not in accordance with the experimental results. As shown by Vinogradova, et al. ${ }^{45}$ with $i-\mathrm{Bu}_{3} \mathrm{Al}$ VA forms a more stable complex than MMA but VA hardly differs from $\mathrm{AN}$ in its complexing ability. Hence, one may suppose that due to steric considerations $\mathrm{CH}_{3} \mathrm{Li}$ has a much higher acceptor capacity than $\left(\mathrm{CH}_{3} \mathrm{Li}\right)_{4}$ or $\mathrm{R}_{3} \mathrm{Al}$. ${ }^{*}$ One can assume for bases and relatively weak acids which yield complexes whose energy is close to van der Waals interaction energy that the mutual arrangement may differ from the arrangement in Figures 3-5. In these cases the geometry may correspond to the traditional ideas. In these circumstances the conjugation in the molecule of base leads to a weakening of the complex. It is known that in contrast to the behavior of aliphatic esters aromatic esters do not form complexes with weak acids such as $\mathrm{Sn}$ - and Ti-halogenides. ${ }^{48}$ On the other hand, both ester types form complexes of comparable stability with relatively stronger acids such as Al- and Ga-halogenides. Hence, it is possible that the existing in reality strong acid occupies an intermediate position between a weak acid and the unrealizably strong monomeric $\mathrm{CH}_{3} \mathrm{Li}$. The contributions of the resonance

* It is also possible that, using the CNDO/2method which may underestimate the repulsions, we find stronger activity of both complexing agents and in particular stronger acidity of the acid than is actually found experimentally. and the van der Waals energies to the total energy of the formation of the complex with a strong acid are comparable. This means that the statistic weights of both conformations (the traditional one and that given in Figure 4) become close to each other. In the traditional conformation the complexes of conjugated bases are less stable than the complexes of unconjugated ones but in the conformation shown in Figure 4 the complexes with conjugated bases are more stable.

Consider now the $\mathrm{Li}-\mathrm{C}$ bond in $\mathrm{CH}_{3} \mathrm{Li}$ and in its complexes. The "rigidity" of this bond and its cause were mentioned above. Proceeding from the linearity of the relationship between the bond length $r$ and the corresponding contribution of $E_{i k}$ to the energy of the system and having found from Figure $1 r(\mathrm{Li}-\mathrm{C})-1.89=$ $0.21\left(E_{\mathrm{Li}-\mathrm{C}}+425\right) / 135$, we come to the following values for the $\mathrm{CH}_{3} \mathrm{Li} \cdot \mathrm{M}$ complexes:

\begin{tabular}{cccccc}
\hline & FA & A & VF & MA & AN \\
\hline$E_{i k}, \mathrm{kcal} / \mathrm{mol}$ & -414 & -408 & -410 & -403 & -404 \\
$\begin{array}{r}\text { Elongation of } \\
r(\mathrm{Li}-\mathrm{C}), \AA\end{array}$ & $0.01_{7}$ & $0.02_{7}$ & $0.02_{4}$ & $0.03_{5}$ & $0.03_{5}$ \\
\hline
\end{tabular}

The $\mathrm{Li}-\mathrm{C}$ bond in these complexes remaines practically undeformed.

\section{DISCUSSION}

In conclusion we shall summarize the restrictions associated with the inadequacy of the model used. First of all the acidity of the Lewis acid selected is too high to be probable. Actually the molecules of these strong acids inevitably aggregate and this leads to a screening of their acid positions. The use of a tetramer instead of a single $\mathrm{CH}_{3} \mathrm{Li}$ molecule is restricted by the capabilities of the computer. On the other hand, the use of an acid of the highest acidity has its advantages. All effects found by the calculation become very pronounced, free from secondary phenomena and, hence, are clear for discussion. Furthermore, it is clear that our calculations may be directly compared only with gas phase reactions since the presence of solvent molecules was not taken into account. Complexation in nonpolar solvents and in the 
gas phase proceeds in a similar manner. ${ }^{49}$. However, considering complex formation in polar solvents, one should calculate the solvation energy and its change in the course of the complexation and take into account specific interactions between the solvent molecules and the participants of the complexation. At present these calculations can hardly be made with satisfactory accuracy. Nevertheless one may tentatively suggest that solvation, being a secondary phenomenon, does not invert the primary phenomena: the charge distribution in the complex components and its change induced by complexation. However, this means again that in our results only the trends are entirely correct. Concerning the variation procedure, we should bear in mind that only the position of $\mathrm{CH}_{3} \mathrm{Li}$ with respect to $\mathrm{FA}$ or $\mathrm{AN}$ was varied. The following operations must be included in this procedure: (a) variation of the $\mathrm{CH}_{3} \mathrm{Li}$ position with respect to other $\mathrm{CB}$; (b) rotation of $\mathrm{CH}_{3} \mathrm{Li}$; (c) variation of the bond lengths and valence angles of all components during the complexation. The last but not the least factor which could influence our calculated data is the accuracy of the calculation method. ${ }^{10-13}$ The control of our results $a b$ initio would be desirable but this control can hardly be made in the near future. As for the semiempirical calculation methods which can reproduce the properties of chemical compounds with satisfactory accuracy for a chemist, ${ }^{50}$ so far these methods are known only for hydrocarbons. ${ }^{50,51}$ Expecting the development of methods which will be applicable to molecules containing heteroatoms, we intend to control our results by some other semiempirical methods of quantum chemistry (see, for instance, ref 32).

Acknowledgement. The authors wish to thank the Leningrad Division of the Central Economical Mathematical Institute of the Academy of Sciences of the USSR for permission to use its computer "Minsk-2M" and the unknown referees for useful remarks.

\section{REFERENCES}

1. Yu. Ye. Eizner, S. S. Skorokhodov, and T. P. Zubova, Eur. Polym. J., 7, 869 (1971).
2. B. L. Erussalimsky, IUPAC Intern. Symp. on Macromol. Chem. Plenary and Main Lect., Akad. Kiadó, Budapest, 1971, p. 281.

3. B. L. Erussalimsky, V. N. Krasulina, and Yu. Ye. Eizner, Vysokomol. Soedin., Ser. B, 12, 327 (1970).

4. B. L. Erussalimsky, V. N. Krasulina, and I. L. Artamonova, V Intern. Conference on Organomet. Chem., Moscow, 1971, 1, 147.

5. L. V. Zamoiskaya, S. I. Vinogradova, and E. B. Milovskaya, Vysokomol. Soedin., Ser. A, 13, 1484 (1971).

6. K. Starovieyski, S. Pasynkiewicz, and E. Jankowska, J. Organometal. Chem., 22, 283 (1970).

7. H. Lewis and T. L. Brown, J. Amer. Chem. Soc., 92, 4664 (1970).

8. M. Morton, L. J. Fetters, and R. A. Pett, Macromolecules, 3, 327 (1970).

9. Ch. B. Tsvetanov, V. N. Zgonnik, B. L. Erussalimsky, and I. M. Panaiotov, Vysokomol. Soedin., Ser. B, 14, 404 (1972); Lieb. Ann., 763, 53 (1972).

10. J. A. Pople, D. P. Santry, and G. A. Segal, $J$. Chem. Phys., 43, S 130, (1965).

11. J. A. Pople and G. A. Segal, ibid., 43, S 136 (1965).

12. J. A. Pople and G. A. Segal, ibid., 44, 3289 (1966).

13. J. A. Pople and D. L. Beveridge, "Approximate Molecular Orbital Theory," McGraw-Hill, New York, N. Y., 1970.

14. R. B. Davidson, W. L. Jorgenson, and L. C. Allen, J. Amer. Chem. Soc., 92, 749 (1970).

15. H. Betsuyaki, J. Chem. Phys., 50, 3118 (1969).

16. W. H. Hehre and J. A. Pople, J. Amer. Chem. Soc., 92, 2191 (1970).

17. H. Imamura, K. Morio, M. Oki, and T. L. Kunii, Tetrahedran Letters, 4575 (1970).

18. L. E. Sutton, "Interatomic Distances," Spec. Publ. No. 11, Chem. Soc., London, 1958.

19. L. Andrews, J. Chem. Phys., 47, 4834 (1967); H. Lewis and T. L. Brown, J. Amer. Chem. Soc., 92, 4664 (1970).

20. W. B. Pearson, Canad. J. Phys., 32, 708 (1954).

21. E. A. Owen and G. I. Williams, Proc. Phys. Soc., 67, 895 (1954).

22. J. Krug, H. Witte, and E. Wölfel, Z. Phys. Chem. (N.F.), 4, 36 (1955).

23. L. Pauling, "The Nature of the Chemical Bond," Cornell Univ. Press Ithaca, N. Y. 1960.

24. G. R. Peyton and W. H. Glaze, Theor. Chim. Acta (Berl.), 13, 259 (1969).

25. A. H. Cowley and W. D. White, J. Amer. Chem. Soc., 91, 34, (1969). 
26. G. A. Segal, J. Chem. Phys., 47, 1899 (1967).

27. H. Dietrich, Acta Crystallogr, 16, 681 (1963).

28. P. A. Kolmar, J. F. Liebman, and L. C. Allen, J. Amer. Chem. Soc., 92, 1142 (1970).

29. W. N. Lipscomb, "Boron Hydrides," New York, N.Y. 1963.

30. L. M. Seitz and T. L. Brown, J. Amer. Chem. Soc., 88, 2174 (1966).

31. L. D. McKeever, R. Waack, M. A. Doran, and E. B. Baker, ibid., 90, 3244 (1968); 91, 1057 (1969).

32. T. L. Brown, L. M. Seitz, and B. Y. Kimura, ibid., 90, 3245 (1968).

33. T. A. Koopmans, Physica, 1, 104 (1934).

34. B. J. Nicholson, Advan. Chem. Phys., 18, 249 (1970).

35. K. Takaji and T. Oka, J. Phys. Soc. Japan, 18, 1174 (1963).

36. N. P. Borisova, G. B. Erussalimsky, and Yu. Ye. Eizner, Zh. Strukt. Khim., 14, 855 (1973).

37. C. A. Coulson, "Valence," Oxford Univ. Press, 1961.

38. R. Wagner, J. Fine, J. W. Simmons, and J. H. Goldstein, J. Chem. Phys., 26, 634 (1957).

39. T. Ukaji, Bull. Chem. Soc. Japan, 32, 1275 (1959).

40. J. A. Pople and M. Gordon, J. Amer. Chem.
Soc., 89, 4253 (1967)

41. N. M. Geller, B. L. Erussalimsky, T. P. Zubova, V. N. Krasulina, V. A. Kropachev, S. S. Skorokhodov, and Yu. Ye. Eizner, Thesis of the XVI Conference of the Institute of High Molecular Weight Compounds of the Academy of Science, USSR, Leningrad, 1970, p. 10.

42. B. L. Erussalimsky, "Ionic Polymerization of Polar Monomers" Nauka, Leningrad, 1970.

43. C. C. Costain and B. P. Stoicheff, J. Chem. Phys., 30, 777 (1959).

44. N. M. Geller, G. B. Erussalimsky, V. A. Kropachev, and Yu. Ye. Eizner, to be published.

45. S. I. Vinogradova, V. M. Denisov, and A. I. Koltzov, Zh. Org. Khim., 42, 1031 (1972).

46. E. B. Milovskaya, L. V. Zamoiskaya, and S. I. Vinogradova, Eur. Polym. J., 6, 1589 (1970).

47. E. B. Milovskaya, E. L. Kopp, O. S. Mikhailycheva, V. M. Denisov, and A. I. Koltzov, Polymer, 13, 288 (1972).

48. E. N. Guryanova, Usp. Khim., 37, 1981 (1968).

49. J. M. Godenow and M. Tamres, J. Chem. Phys., 43, 3393 (1965).

50. M. J. S. Dewar, Angew. Chem., 82, 960 (1970).

51. H. Fischer and H. Kollmar, Theor. Chim. Acta (Berl.), 13, 213 (1969). 